\title{
Treat or Enhance Cognitive Restraint in Individuals Suffering from Overweight or Obesity? Systematic Revue of the Literature
}

\author{
S. Julien Sweerts ${ }^{1,2}$, G Apfeldorfer ${ }^{2}$, L. Romo ${ }^{1,3}$, K.Kureta-Vanoli ${ }^{2}$ \\ ${ }^{1}$ Laboratoire De Psychologie Clinique, EA 4430 (EVACLIPSY), Université Paris Ouest Nanterre La Défense, FRANCE \\ ${ }^{2}$ G.R.O.S., Groupe De Réflexion Sur l'Obésité Et Le Surpoids, PARIS, FRANCE \\ ${ }^{3}$ CMME, Centre Hospitalier Sainte-Anne, PARIS, Unité Inserm U 894 CPN, FRANCE
}

Received: March 14, 2016; Accepted: April 27, 2016; Published: May 23, 2016

*Corresponding author: S JULIEN SWEERTS, Association GROS, 37 rue des Mathurins,75008 PARIS, FRANCE, Tel: 003-368-7069-940; E-mail: sabrinajuliensweerts@gmail.com

\begin{abstract}
Cognitive Restraint, a mind control over food intake in order to lose or maintain weight, leads to harmful consequences in individuals suffering from overweight or obesity. These consequences include an alteration of internal perceptions of hunger and satiety, a disinhibition, an emotional dysregulation and a decrease in selfesteem and body satisfaction. Nevertheless, the systematic review on the subject highlights a lack of consensus. In fact, many studies suggest that flexible control, or even an increase in self-control could be efficient to lose weight and improve an individual's psychological factors. After presenting each point of view and its arguments as well as the internal validity of studies, we will discuss promising future research perspectives.
\end{abstract} Eating

Keywords: Cognitive restraint; overweight; Obesity; Intuitive

\section{Introduction}

Obesity is a chronic disorder characterized by excess body fat and increases health risks while decreasing life expectancy. Its causes are complex, multi factorial, and still unclear. Dietary modifications play an undeniable role in the recent emergence of obesity: increased portion sizes with higher energy density as well as a greater food availability. However, these changes do not similarly affect people [1]. In addition, we need to understand what enables people to cope with this new environment while maintaining a normal physiological body weight. This could help establish an effective and appropriate protocol to prevent this chronic disease. Weight loss diets nowadays proved to be ineffective and harmful on the long term. Nonetheless, what are the other available alternatives? The discontinuation of Cognitive Restraint (CR) seems to be a promising therapeutic strategy however current research seem to take the opposite direction.

The systematic review was designed in order to provide an overview of the literature on the subject. We will then discuss future therapeutic perspectives.

\section{Methods}

We carried out a systematic review of the literature on CR. Research criteria were set in advance. Only articles in English or French were reviewed. Terms and data bases are presented in table 1. Reference lists of articles were manually investigated to identify studies potentially relevant for inclusion. The last search was conducted on the $15^{\text {th }}$ of October 2015 .

\section{Definition of Cognitive Restraint}

Prior to 1975 , the scientific literature mainly used to compare obese with normal-weight subjects or subjects with or without an eating disorder. This period was followed by the emergence of "unrestrained eaters", who have "normal" eating behaviors versus "restrained eaters", who are normal-weight individuals with similar eating behavioral patterns than those of obese people [2]. After this first observation, the definition of a "restrained eater" has developed and came into a consensus: it describes someone who constantly deliberately controls his food intake in order to maintain or lose weight [3]. This person could have a normal bodyweight, be overweight or even obese and the dietary control could be efficient or ineffective [4]. Here, the intention to control food intake is the main characteristic. It is not surprising that $\mathrm{CR}$ is most often identified in individuals

Table 1 : Number of studies found in data bases according to the search term used.

\begin{tabular}{|l|c|c|}
\hline Term & $\begin{array}{c}\text { Number of studies } \\
\text { in Eb cost }\end{array}$ & $\begin{array}{c}\text { Number of } \\
\text { results Psych } \\
\text { INFO }\end{array}$ \\
\hline Restrained eating & 14628 & 885 \\
\hline Restraint eating & 30713 & 2258 \\
\hline $\begin{array}{l}\text { Restrained and unrestrained } \\
\text { eating }\end{array}$ & 2315 & 262 \\
\hline Restrained eating & 4046 & 437 \\
\hline
\end{tabular}


who are following a slimming diet, who overeat or whose weight fluctuates frequently [3].

The intention to control food intake in order to maintain weight is generally evaluated with a self-report. However, the behavioral study of individuals who limit their food intake is evaluated by in vivo food priming techniques [5]. These techniques are divided into two periods: first, individuals are given small amounts of highly energetic foods (milkshakes for example). Then, they are given food at will while measuring the amount of ingested food.

\section{Consequences of Cognitive Restraint}

Dysregulation of Internal Perceptions Of Hunger And Satiety: Mentally controlling energy intakes will impair a person's ability to heed physiological signals of hunger and satiety, which are essential for homeostatic regulation [7]. The individual won't stop eating because he's full, but because he decided to stop. Restrained eaters switch from a regulation based on following physiological perceptions of hunger and satiety to a regulation deliberately mentally controlled $[2,8]$. If the restrained eater starts neglecting his feelings, he'll have to use other variables to control his food intake. The results of a study on the visual influence of portion sizes on food intake seemed interesting [9]. During this study, participants were initially served a same-sized slice of pizza. Then, they were allowed to eat cookies at will. Due to visual manipulation, the slice of pizza appeared larger for some participants and smaller for others. It turned out that restrained eaters tended to eat more cookies when the pizza slice was perceived as large, whereas unrestrained eaters tended to eat less cookies. We can also raise the question of the methods used by restrained eaters to regulate themselves when ignoring their feelings and when their visual references are unreliable.

It seems that ignoring the feeling of hunger, a physiological signal indicating a deficit in the body's energy stores, is followed by four consecutive phases table 2 .

Mental control of hunger and satiety sensations will eventually lead to the inability to heed these sensations and to an increase of binge crises and sense of losing control. In fact, regulation that is normally realized using consistency, "the more I eat, the less I feel like eating", will be performed using tendency, "the more I eat, the more I feel like eating" [10].

Disinhibition: According to the restraint theory [11], controlling food intake requires substantial attention and cognitive inhibitions. Nonetheless, this mental control might not work under conditions of stress, negative emotions, energetic preload, or alcohol consumption, and will lead to a state of important disinhibition $[2,6,12,13]$.

In fact, this disinhibition in restrained eaters has been previously proven in many studies. Food priming will induce a disinhibition which results in the increase of food consumption when food is offered at will. This phenomenon is not observed in unrestrained eaters for whom food priming will actually reduce food intake $[5,9,14]$. CR increases the probability of consequent overeating [15]. Avoidant coping style could be a moderating variable in the CR/disinhibition link [16]. It seems that restrained eaters who avoid to eat [16], or to think about food [17], are particularly vulnerable to overeating. However, many studies suggest that the link between CR and disinhibition is not as strong as it appears. We will discuss this later though it is important to note that disinhibition is more pronounced in women who have high levels of eating disorders compared to the male general population $[3,18]$.

Emotional Dysregulation: The restrained eater has a double trouble: not only does he eat more than he intends but he also ends up feeling worse [19]. Guilt is among the negative emotions felt: guilt after eating a high-calorie food [20,21], guilt after eating more than intended [22], guilt after failing to follow the rules initially set [23]. At this point, food is no longer a source of energy or pleasure but causes anxiety and guilt [24]. In addition, food will no longer play its natural role as an emotional regulator. Indeed, eating provides an emotional regulation in all mammals. However, individuals that use CR fail to reduce their anxiety levels by eating [2]. Not only emotional regulation is no longer effective, but even thinking about eating will generate anxiety and eatingrelated guilt. Thus, the individual will end up feeling worse and might eat to calm down his emotions, to avoid this unpleasant

Table 2. The four phases of cognitive restraint by Apfeldorfer \& Zermati, 2001.

\begin{tabular}{|l|l|l|l|}
\hline Phase & Perception of sensations & Behavior & Verbatim \\
\hline Low CR & Perceived food sensations and emotions. & $\begin{array}{l}\text { The eater deliberately ignores } \\
\text { sensations. }\end{array}$ & $\begin{array}{l}\text { I know I'm hungry, but I } \\
\text { have to stop eating. }\end{array}$ \\
\hline Moderate CR & $\begin{array}{l}\text { Food sensations and emotions are still } \\
\text { perceived but not followed. }\end{array}$ & $\begin{array}{l}\text { The eater can't follow his } \\
\text { sensations anymore due to } \\
\text { induced emotions with very } \\
\text { negative content. }\end{array}$ & $\begin{array}{l}\text { I know I'm not hungry } \\
\text { anymore, but I can't stop. }\end{array}$ \\
\hline Severe CR & Food sensations and emotions are not \\
perceived anymore. & $\begin{array}{l}\text { The eater will painfully struggle } \\
\text { to sustain mental control, not } \\
\text { give in to the invasion of induced } \\
\text { emotions and emotions not } \\
\text { related to food. }\end{array}$ & $\begin{array}{l}\text { I don't know if I'm still } \\
\text { hung or I ate enough. }\end{array}$ \\
\hline Decompensated CR & Food sensations and emotions are not & $\begin{array}{l}\text { The eating behavior is under the } \\
\text { control of emotions not related } \\
\text { to food and induced emotions. }\end{array}$ & $\begin{array}{l}\text { I eat without being } \\
\text { hungry and I can't control } \\
\text { anything. }\end{array}$ \\
\hline
\end{tabular}


emotional experience and the thoughts associated to it [25]. The more he eats, the worse he feels, and the worse he feels the more he eats. This vicious circle and sense of lack of control might be explained by the four phases of CR, where eating behaviors are completely managed by emotions that are not related to food, or induced by food. Some studies found that higher CR predicted binge eating episodes [26], bulimic pathologies [27], eating disorders in general [28-30], and higher risks of becoming an emotional eater [31].

Self-Esteem and Body Satisfaction: The restrained eater

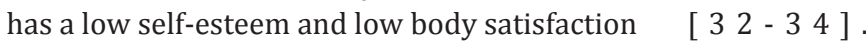
In fact, it seems that CR affects body dissatisfaction indirectly through the mediation of self-esteem [35].

\section{Clinical Implications of Studies on Cognitive Restraint}

Discontinuing Cognitive Restraint? Hypothesis Scientifically Tested: According to the literature review, discontinuing CR could improve body image and weight control and decrease disordered eating behaviors. Some studies have empirically tested this hypothesis [36-40]

Studies Methods: Suggested programs for unrestrained eaters are very heterogeneous table 3 . They can go from brainstorming sessions on "how to live in a world promoting thinness" to "how to live a healthier life" or working on hunger and satiety feelings. The methodology of working on hunger sensations are not elaborated. Nothing proves that asking the patient to follow his food sensations of hunger or satiety is enough to ensure his success. On the contrary, results of the studies presented in table 4 show weight gain or no weight loss in groups including unrestrained eaters. This suggests that regulation might not be working appropriately or that individuals are at their physiological weight (see homeostatic regulation).
Furthermore, two studies question the reality of non-CR. Rapoport et al. (2000) [39] recommended to eat less fat, which could be considered CR in the sense that the participant had to control his fat intake in order to lose weight. The purpose of the study of Goodrick (1998) [39] was to progressively decrease fat intakes in a way it is not perceived as a punishment, but as pleasant and without restriction.

Did these studies compare adequately what they thought they were comparing? What about their internal validity?

Studies Results: These studies failed to demonstrate the benefits of non-CR therapy compared to therapy based on CR. At a behavioral level, the severity of the disorders decreased in both treatments with an improvement of psychological factors.

When it comes to weight loss, three studies showed a significant advantage of the conventional therapy based on CR.

Conclusions of Studies: The conclusions of each of these studies are inconsistent. Some found both therapies based on cognitive and non-CR to be inefficient on weight loss [36]. Others were either slightly in favor of non-cognitive therapy [36] or highly in favor of CR therapy and its effect on bodyweight [38]. The study of Bacon et al. (2005) [40] is interesting in the sense significant experimental attrition was found in the CR group (41\%) compared to the non- CR group (8\%). However, we also question here the internal validity of this study. Is it accurate to compare the results when attrition is very high in one group?

Despite their significant limits, it seems that the major conclusion of these studies is that CR helps to lose more weight than non-CR and that it has the same effects on psychological variables [41]. The initial hypothesis that non-CR treatment would allow better body image, less disordered eating habits, and more efficient weight loss was not verified in five consecutive

Table 3. Conducted programs in restrained and unrestrained eaters.

\begin{tabular}{|c|c|c|}
\hline \multirow[b]{2}{*}{ Studies } & \multicolumn{2}{|c|}{ Conducted program } \\
\hline & CR Group & Non-CR Group \\
\hline Goodrick, 1998 & Rules= Eat less fat and more complex carbohydrates. & $\begin{array}{l}\text { Being fat in a thin society, self-esteem, } \\
\text { social support. Goal to a healthier and } \\
\text { more dynamic lifestyle. Physical exercise } \\
\text { progressively increased. }\end{array}$ \\
\hline \multicolumn{3}{|l|}{$\mathrm{P}=$ hyperphagia } \\
\hline Rapoport, 2000 & CBT + dietary guidelines & $\begin{array}{l}\text { CBT + healthier lifestyle (more sport, } \\
\text { less fat). }\end{array}$ \\
\hline \multicolumn{3}{|l|}{ P: $\mathrm{BMI}>28$} \\
\hline Lowe, 2001 & CBT + dietary guidelines & Work on hunger sensation. \\
\hline \multicolumn{3}{|l|}{ P: obese > 27.7} \\
\hline Bacon, 2002 & Dietetic program & Eat according nutritional feelings \\
\hline Bacon, 2005 & Dietetic program & Eat according to nutrition feelings \\
\hline P. $\mathrm{BMI}>30, \mathrm{CR}>15$ & & \\
\hline
\end{tabular}


Table 4 : Results of different studies.

\begin{tabular}{|c|c|c|c|}
\hline \multirow[b]{2}{*}{ Studies } & \multicolumn{2}{|l|}{ Results } & \multirow[b]{2}{*}{ Authors' conclusion } \\
\hline & $\begin{array}{l}\text { On behavior and psychological } \\
\text { variables }\end{array}$ & On weight & \\
\hline \multirow[t]{2}{*}{ Goodrick, 1998} & $\begin{array}{c}\text { Decrease of BES (binge eating scale) scores } \\
\text { in both groups > control group }\end{array}$ & $\begin{array}{c}\text { At 6months: }-500 \mathrm{~g} \mathrm{RC},+1,35 \mathrm{~kg}, \\
\text { non-CR }\end{array}$ & $\begin{array}{l}\text { Decrease in the severity of binge of both groups. } \\
\text { Both techniques are inefficient for weight loss. }\end{array}$ \\
\hline & & $\begin{array}{l}\text { At } 18 \text { months: }+1 \mathrm{~kg} / \text { initial } \\
\text { bodyweight in both groups }\end{array}$ & \\
\hline \multirow[t]{2}{*}{ Rapoport, 2000} & $\begin{array}{l}\text { Decrease in depression and stress. Higher } \\
\text { increase in self-esteem than non-CR group. }\end{array}$ & Decrease in both groups. & $\begin{array}{l}\text { Modest benefits of non-conventional methods } \\
\text { (non-CR). }\end{array}$ \\
\hline & & $-3,8 \mathrm{~kg}$ CR; $-2,1 \mathrm{~kg}$ non-CR & \\
\hline \multirow[t]{2}{*}{ Lowe, 2001} & CR: increase in CR; & CR: -7,47kg; & $\begin{array}{l}\text { Restrictive dieting may increase susceptibility to } \\
\text { overeating. It may be beneficial, prior to dieting, } \\
\text { to teach individuals how to identify and cope } \\
\text { with a stimulus triggering overeating. }\end{array}$ \\
\hline & Non-CR: Decrease in CR & Non-CR: $+60 \mathrm{~g}$ & \\
\hline \multirow[t]{2}{*}{ Bacon, 2002} & Improvement in both groups & CR: $-4,9 \mathrm{~kg}$ & $\begin{array}{l}\text { No differences except with attrition ( } 41 \% \text { RC vs } \\
8 \% \text { non RC). Strategy of non-CR recommended. }\end{array}$ \\
\hline & & Non-CR: $+300 \mathrm{~g}$ & \\
\hline \multirow[t]{2}{*}{ Bacon, 2005} & CR: increase in CR; & $\begin{array}{l}\text { At 1year: CR: 5,2kg \& non-CR: } \\
\text { +0,3 kg; }\end{array}$ & $\begin{array}{l}\text { Encouraging size acceptance, decreasing in } \\
\text { dieting behavior, and increase in awareness to } \\
\text { body signals seem efficient in improving health } \\
\text { risk indicators for obese women with high CR. }\end{array}$ \\
\hline & Non-CR: decrease in CR. & $\begin{array}{l}\text { At } 2 \text { years: CR: }-3,2 \mathrm{~kg} \& \text { non- } \mathrm{CR}: \\
+0,4 \mathrm{~kg} .\end{array}$ & \\
\hline $\begin{array}{l}\text { R: Cognitive } \\
\text { estraint }\end{array}$ & & & \\
\hline
\end{tabular}

studies [36-40]. The negative outcome of CR was not confirmed except when it came to experimental attrition [40] and enhanced sensitivity to overeating [38]. These results imply a questioning of the CR theory consensus, which is largely debated.

Questioning the Harmfulness of Cognitive Restraint: The effects of CR are contradictory according to the different methodologies, instruments and studied population [41]. CR is implemented when a person wants to lose weight, thus when they are overeaters. It only induces overeating after caloric preload when both CR and disinhibition scores are very high [42, 43]. More precisely, it seems that restrained eaters only consume more food when they are impulsive and male [44]. Furthermore, CR seems to occur with disordered eating behaviors, but doesn't seem to provoke them $[45,46]$.

There are more and more arguments in favor of CR on bodyweight. It seems CR is associated with lower body weight in obese individuals [47-50]. It also seems that the latter, exhibiting higher disinhibition, have a lower weight associated with higher scores on CR [51-54]. Finally, individuals that are obese or have high disinhibition scores seem to have a better mental control of food intakes, displaying a significant weight benefit.

A New Concept: Flexible Cognitive Restraint: The concept of flexible CR has emerged in the midst of much debate.

In flexible control, fattening foods are allowed in limited quantities and are not totally banned. It seems to be associated with successful weight loss without food craving and without including the inconveniences of rigid control [55]. It is also associated with a lower body mass index and a greater weight loss than the rigid CR [56-58]. Flexible CR only results in preoccupying cognitions with food (sugar, fat, and calories). Rigid restraint leads to cognitions with food in general and body shape, which could result in compulsions [58]. Flexible restraint seems effective on weight loss and its maintenance [58].

Nevertheless, this concept is also contested. In fact, a prospective investigation over three years found that flexible and rigid restraint were similarly correlated to weight loss and improvement in eating habits (e.g. decreased sugar and fat intakes, implementation of cognitive strategies to control weight, increase of physical exercise and decrease in time spent watching television) [59]. Another 3-year prospective study showed an increase of $138 \%$ of the risk of substantial weight gain (greater than $3 \mathrm{~kg}$ ) and an increase of $49 \%$ of the risk of body fat gains in women who did not increase in restrained eating compared with women who did [60].

Both these studies are in favor of maintaining and reinforcing CR in patients for better weight control. However, they do not evaluate their patients' quality of life nor psychological factors such as depression, self-esteem and body satisfaction. In fact, it seems that their conclusions are a bit hasty. It actually seems very rational for an individual to gain weight over three years when he is not mentally and deliberately controlling his food intake and chooses not to heed his hunger and satiety sensations. From a strictly physiological point of view, the basal metabolism could 
adapt to mentally controlled food intake by decreasing. Thus, the same energy intake will naturally induce weight gain that is only reversed if the person eats even less. These studies seem to show that flexible and rigid restraint should be progressively increased with time to prevent weight gain. They actually end up encouraging restriction. Is it appropriate and exhaustive? Would it not have been more accurate to conclude that a restrained eater should increase his CR with time not to gain weight? Still, despite their limits, these studies added arguments against treatments based on discontinuing $\mathrm{CR}$.

\section{Intuitive Eating, Another Alternative}

Alongside flexible CR, another alternative to rigid CR holds the attention of researchers: intuitive eating, defined by eating based on physiological hunger and satiety cues rather than situational and emotional cues [61]. This eating behavior is considered flexible and adaptive [62]: if a person eats more at a particular meal, he will naturally feel less hungry at the following meal and will automatically eat less. In addition, it seems that individuals who adopt intuitive eating have less food concerns, and are less puzzled by the quality (good and bad) of food. They will base their food choices on culinary pleasure, health, energy, endurance, or performance [62]. Some studies found a positive correlation between intuitive eating and health and well-being [63]. On one hand, intuitive eating seems to be negatively correlated to eating disorders, disinhibition, body mass index, cardio-vascular risks, weight and shape concerns, and negative affects. On the other hand, intuitive eating was positively correlated to high levels of high density lipoproteins (HDL), culinary pleasure, positive feelings and emotions, quality of life satisfaction and higher selfesteem $[47,61,64-70]$.

Nevertheless, the majority of studies evaluated participants whose eating behavior was initially based on intuitive eating and compared them to individuals with flexible or rigid CR [71]. However, few studies evaluated the outcome of a psychological intervention that would aim at increasing intuitive eating. These studies include the studies of Bacon and his colleagues [39, 40], with its limited effectiveness on weight and previously mentioned limits.

It seems that intuitive eating is an interesting area of research on health and well-being. However, it is crucial to focus on methodology to establish this new eating behavior.

\section{A New Clinical Orientation: Self-Control}

Should CR or bodyweight be increased; that is the new dilemma. Until this day, nothing seems to work on bodyweight better than self-control. The new scientific problematic has now become: how to successfully increase CR? [72]. Exercise could help restrained eaters to maintain control over their appetite, creating a greater energy deficit compared to unrestrained eaters [73]. In general, higher dispositional self-control could facilitate successful restrained eating $[74,75]$. The new area of treatment is now self-regulation and increase in self-control through controlled exposure techniques or other upcoming techniques [41]. A recent study showed that neuropsychological inhibition trainings of automatic response to a food stimulus would immediately decrease potato chips intake that were initially offered at will [76]. Some authors state that: 1) human beings have the ability to better control their food intakes and bodyweight; 2) it is aberrant to highlight the dangers of dieting while it is crucial to stop the progression of over-consumption of food and obesity epidemics [77]. The negative consequences of $\mathrm{CR}$ have been debated with weight benefit being the principle argument.

\section{Discussion}

CR is an issue causing controversy for the past forty years. On one hand, it induces an energetic, emotional and behavioral Dysregulation. On the other hand, it seems that CR is fundamental for successful weight loss. However, it should be flexible and only induce weight loss without negative consequences.

Despite arguments in favor and against CR, this literature review doesn't allow the reader to take a stand. First of all, studies comparing treatments of restrained and unrestrained eaters are unclear about the method used to discontinue CR. This significantly negatively influenced their internal validity. Did they truly compare what they thought they were comparing? Furthermore, the longitudinal studies mentioned above (see "A new concept: flexible CR") only evaluate the bodyweight and level of $\mathrm{CR}$ of women on a restrictive diet. They fail to propose any alternative for CR and actually conclude that increasing CR is crucial for limiting weight gain.

Flexible restraint, which is well documented in the literature, is similar to diets usually prescribed by many nutritionists around the world. Unfortunately, results are inconclusive. In $90 \%$ of cases, the effectiveness of a weight-loss diet does not exceed two years, regardless of the type of diet [78]. In fact, a study including 811 participants found that they all significantly lost weight during the first year, irrespectively of the diet's composition (low-fat, high-protein), but started progressively gaining back the weight afterwards. They eventually went back to their initial weight (before dieting) at 24 months [78]. A study analyzing twenty-nine structured weight-loss programs found that the average individual that weighs $100 \mathrm{~kg}$ at the start of the program will only maintain a weight loss of $3 \mathrm{~kg}$ five years after completing the program [79]. Another study including 2400 individuals showed that $94 \%$ of successful weight losers gained their weight back after two years [80]. In fact, dieting will make you fat in the long term [81]. When examining the weight of 15000 kids, aged 9 to 14 years and with a mean body mass index of 19 (matched for weight and age), for three years, it seemed that the ones that followed a diet gained more weight than the ones who did not follow a diet [81]. A recent study including 8824 participants concluded that diets may contribute to the risk of future obesity and weight gain [82]. Carper et al. (2000) [83] found that mothers who are on a diet might induce their daughters' weight gain.

Finally, eating is a physiological, psychological and cultural act. We eat to meet the energy and nutritional needs of our organism but also for comfort, fun and to share special moments 
with families and friends. How are we supposed to imagine that adopting a non-physiological behavior, that is restrictive and socially isolating on the long run, could be the optimal solution for our patients' well-being?

Furthermore, it seems important to establish a specific protocol and guidelines for discontinuing CR that will allow weight regulation based on following one's hunger and satiety sensations. The effects of such a protocol on weight fluctuations and other psychological factors (to be defined) should be analyzed.

\section{Conclusion}

CR could lead to adverse consequences in individuals suffering from overweight or obesity. These consequences include an alteration of internal perceptions of hunger and satiety, a disinhibition, and a decrease in self-esteem and body satisfaction. Nevertheless, the systematic review of the literature highlights the lack of consensus on the subject. In fact, some studies found that flexible restraint or increased self-control could be effective on weight-loss and enhance a person's psychological factors. However, do these studies prove adequately what they wanted to prove? Is it possible that a non-physiological behavior, that is restrictive and socially isolating on the long run, could be the optimal solution for our patients' well-being? Before coming to that conclusion, ignoring the unpromising results of studies on weight-loss diets, further research is needed about intuitive eating, which seems more physiological and adaptive.

\section{References}

1. Wardle J and D Boniface. Changes in the distributions of body mass index and waist circumference in English adults, 1993/1994 to 2002/2003. International Journal of Obesity. 2008;32(3):527-532.

2. Herman CP and J Polivy. Anxiety, Restraint, and Eating Behavior. 1975;84(6):66-72.

3. Lowe MR and JG Thomas. Measures of restrained eating: Conceptual evolution and psychometric update., in Handbook of assessment methods for obesity and eating behaviors. D Allison and ML Baskin Editors. SAGE:New York. 2009;137-185.

4. Stice E, Robyn Sysko, Christina A, Roberto and Shelley Allison Are dietary restraint scales valid measures of dietary restriction? Additional objective behavioral and biological data suggest not. Appetite. 2010;54(2):331-339. doi:10.1016/j.appet.2009.12.009

5. Stroebe W. Restrained eating and the breakdown of selfregulation in Dieting, overweight and obesity: Selfregulation in a food-rich environment. W Stroebe Editor. American Psychological Association: Washington DC. 2008;115-139.

6. Herman CP and D Mack. Restrained and unrestrained eating. J Pers. 1975;43(4):647-660.

7. Schwartz GE. Biofeedback, self-regulation, and the patterning of physiological processes. Am Sci. 1975; 63(3):314-324.

8. Spoor ST, Stice E, Bekker MH, Van Strien T, Croon MA and Van Heck GL. Relations between dietary restraint, depressive symptoms, and binge eating: A longitudinal study. Int J Eat Disord. 2006;39(8):700707.

9. Polivy J, CP Herman and R Deo. Getting a bigger slice of the pie. Effects on eating and emotion in restrained and unrestrained eaters. Appetite.

\section{0;55(3):426-430. doi: 10.1016/j.appet.2010.07.015}

10. Apfeldorfer $G$ and JP Zermati. [Cognitive restraint in obesity. History of ideas, clinical description]. Presse Med, 2001;30(32):1575-1580.

11. Herman CP and J Polivy. A boundary model for the regulation of eating. Res Publ Assoc Res Nerv Ment Dis. 1984;62:141-156.

12. Cools J, DE chotte and RJ McNally. Emotional arousal and overeating in restrained eaters. J Abnorm Psychol. 1992;101(2):348-351.

13. Polivy J and CP Herman, Effects of alcohol on eating behavior: influence of mood and perceived intoxication. J Abnorm Psychol. 1976;85(6):601-606.

14. van Strien T, Herman CP, Engels RC, Larsen JK, van Leeuwe JF. Construct validation of the Restraint Scale in normal-weight and overweight females. Appetite. 2007;49(1):109-121.

15. Polivy J and CP Herman. Dieting and binging. A causal analysis. Am Psychol. 1985; 40(2):193-201.

16. Lee JM, L Greening and L Stoppelbein. The moderating effect of avoidant coping on restrained eaters' risk for disinhibited eating: Implications for dietary relapse prevention. Behaviour Research and Therapy. 2007;45(10):2334-2348.

17. Erskine JA and GJ Georgiou. Effects of thought suppression on eating behaviour in restrained and non-restrained eaters. Appetite. 2010;54(3):499-503. doi: 10.1016/j.appet.2010.02.001

18. Ogden J. Effects of smoking cessation, restrained eating, and motivational states on food intake in the laboratory. Health Psychol. 1994;13(2):114-121.

19. De Witt Huberts JC, C Evers and DT de Ridder. Double trouble: restrained eaters do not eat less and feel worse. Psychol Health. 2013;28(6):686-700.doi:10.1080/08870446.2012.751106.

20. Macht M, J Gerer, and H Ellgring. Emotions in overweight and normalweight women immediately after eating foods differing in energy. Physiol Behav. 2003;367-374.

21. Macht $M$ and D Dettmer. Everyday mood and emotions after eating a chocolate bar or an apple. Appetite. 2006;46(3):332-336. doi:10.1016/j.appet.2006.01.014

22. Rozin P, Kabnick K, Pete E, Fischler C, Shields C. The ecology of eating: smaller portion sizes in France Than in the United States help explain the French paradox. Psychol Sci. 2003;14(5):450-454.

23. Tangney JP, and RL Dearing. Shame and guilt. Emotions and social behavior. New York: Guilford Press. 2004;1-273.

24. Rozin P, Fischler C, Imada S, Sarubin A, Wrzesniewski A. Attitudes to food and the role of food in life in the U.S.A., Japan, Flemish Belgium and France: possible implications for the diet-health debate. Appetite. 1999;33(2):163-180.

25. Baer RA, S Fischer, and DB Huss. Mindfulness-based cognitive therapy applied to binge eating: A case study. Cognitive and Behavioral Practice. 2005;12(3):351-358.DOI:10.1016/S1077-7229(05)800574

26. Stice E, K Presnell and D Spangler. Risk factors for binge eating onset in adolescent girls: A 2-year prospective investigation. Health Psychology. 2002;21(2):131-138.

27. Stice E. A prospective test of the dual-pathway model of bulimic pathology: Mediating effects of dieting and negative affect. Journal of Abnormal Psychology. 2001;110(1):124-135.

28. Killen JD, Taylor CB, Hayward C, Wilson D, Haydel K, Hammer L and 
et al. Pursuit of Thinness and Onset of Eating Disorder Symptoms in a Community Sample of Adolescent Girls: A Three-Year Prospective Analysis. International Journal of Eating Disorders. 1994;16(3):227238.

29. Killen JD, Taylor CB, Hayward C, Haydel KF, Wilson DM, Hammer $\mathrm{L}$ and et al. Weight concerns influence the development of eating disorders: A 4-year prospective study. Journal of Consulting and Clinical Psychology. 1996;64(5):936-940.

30. L.K. George Hsu. Epidemiology of the eating disorders. Psychiatric Clinics of North America, 1996;19(4): 681700. doi:10.1016/S0193953X(05)70375-0

31. Polivy J, Herman CP, McFarlane T. Effects of anxiety on eating: Does palatability moderate distress-induced overeating in dieters? Journal of Abnormal Psychology. 1994;103(3):505-510.

32. Martine F. Flament, Erin M. Hill, Annick Buchholz, Katherine Henderson, Giorgio A. Tasca, Gary Goldfield. Internalization of the thin and muscular body ideal and disordered eating in adolescence: The mediation effects of body esteem. Body Image. 2012;9(1):68-75 doi:10.1016/j.bodyim.2011.07.007.

33. Forrester-Knauss C, Perren S, Alsaker FD. Does body mass index in childhood predict restraint eating in early adolescence? Appetite. 2012;59(3):921-926. doi: 10.1016/j.appet.2012.08.026.

34. Wilksch S, Wade TD. Differences between women with anorexia nervosa and restrained eaters on shape and weight concerns, selfesteem, and depression. International Journal of Eating Disorders. 2004;35(4):571-578.

35. Fanchang, K, Yan Zhang, Zhiqi You, Cuiying Fan, Yuan Tian, Zongkui Zhou. Body dissatisfaction and restrained eating: mediating effects of self-esteem. Social Behavior \& Personality. an international journal. 2013;41(7):1165-1170

36. Goodrick GK, Poston WS, Kimball KT, Reeves RS, Foreyt JP. Nondieting versus dieting treatment for overweight binge-eating women. Journal of Consulting and Clinical Psychology. 1998;66(2):363-368.

37. Rapoport L, M Clark and J Wardle, Evaluation of a modified cognitive,Äïbehavioural programme for weight management International Journal of Obesity \& Related Metabolic Disorders. 2000;24(12):1726-1737.

38. Lowe MR, Foster GD, Kerzhnerman I, Swain RM, Wadden TA Restrictive dieting vs. 'undieting': Effects on eating regulation in obese clinic attenders. Addictive Behaviors. 2001;26(2):253-266.

39. Bacon L, Keim NL, Van Loan MD, Derricote M, Gale B, Kazaks A, et al. Evaluating a 'non-diet' wellness intervention for improvement of metabolic fitness, psychological well-being and eating and activity behaviors. International Journal of Obesity \& Related Metabolic Disorders. 2002;26(6):854-865.

40. Bacon L, Stern JS, Van Loan MD, Keim NL. Size acceptance and intuitive eating improve health for obese, female chronic dieters. Journal of the American Dietetic Association. 2005;105(6):929-936.

41. Johnson F, M Pratt, and J Wardle. Dietary restraint and self-regulation in eating behavior. International journal of obesity. 2012:36(5);665674. doi: $10.1038 / \mathrm{ijo} .2011 .156$.

42. Westenhoefer J, Broeckmann P, Münch AK, Pudel V. Cognitive control of eating behaviour and the disinhibition effect. Appetite, 1994:23(1);27-41.

43. Van Strien TA Restraint, Tendency Toward Overeating and Ice Cream Consumption. International Journal of Eating Disorders.

\section{0;28(3):333-338.}

44. Greenwood J, J Broadbent, and M Fuller-Tyszkiewicz. Restrained eaters consume more food only if they are impulsive and male. Eating behaviors. 2014;15(4):582-585. doi: 10.1016/j.eatbeh.2014.08.017.

45. Masheb RM and Grilo CM. On the Relation of Flexible and Rigid Control of Eating to Body Mass Index and Overeating in Patients with Binge Eating Disorder. International Journal of Eating Disorders. 2002;31(1):82-91.

46. Lowe MR and TVE Kral. Stress-induced eating in restrained eaters may not be caused by stress or restraint. Appetite. 2006;46(1):16-21.

47. Bellisle F, Clément K, Le Barzic M, Le Gall A, Guy-Grand B, Basdevant A. The Eating Inventory and Body Adiposity from Leanness to Massive Obesity: A Study of 2509 Adults. Obesity Research. 2004;12(12):2023-2030.

48. Provencher V, Drapeau V, Tremblay A, Després JP and Lemieux S. Eating behaviors and indexes of body composition in men and women from the Québec family study. Obes Res. 2003;11(6):783-792.

49. Cappelleri JC, Bushmakin AG, Gerber RA, Leidy NK, Sexton CC, Lowe MR and et al. Psychometric analysis of the Three-Factor Eating Questionnaire-R21: Results from a large diverse sample of obese and non-obese participants. International Journal of Obesity. 2009;33(6):611-620.doi:10.1038/ijo.2009.74.

50. Foster GD, Wadden TA, Swain RM, Stunkard AJ, Platte P, Vogt RA. The Eating Inventory in obese women: Clinical correlates and relationship to weight loss. International Journal of Obesity \& Related Metabolic Disorders. 1998. 22(8):778-785

51. Williamson DA, Lawson OJ, Brooks ER, Wozniak PJ, Ryan DH, Bray GA and et al. Association of body mass with dietary restraint and disinhibition. Appetite. 1995;25(1):31-41.

52. Hays NP, Bathalon GP, McCrory MA, Roubenoff R, Lipman R and Roberts SB. Eating behavior correlates of adult weight gain and obesity in healthy women aged 55-65 y. Am J Clin Nutr. 2002;75(3):476-483.

53. Dykes J, Brunner EJ, Martikainen PT and Wardle J. Socioeconomic gradient in body size and obesity among women: the role of dietary restraint, disinhibition and hunger in the Whitehall II study. Int J Obes Relat Metab Disord. 2004;28(2):262-268.

54. Hays, NP and SB Roberts. Aspects of eating behaviors "disinhibition" and "restraint" are related to weight gain and BMI in women. Obesity (Silver Spring). 2008;16(1):52-58.doi:10.1038/oby.2007.12

55. Meule A, Westenhöfer J, Kübler A. Food cravings mediate the relationship between rigid, but not flexible control of eating behavior and dieting success. Appetite. 2011;57(3):582-584.doi:10.1016/j. appet.2011.07.013.

56. Westenhoefer J, AJ Stunkard and V Pudel. Validation of the flexible and rigid control dimensions of dietary restraint. Int J Eat Disord. 1999;26(1):53-64.DOI:10.1002/(SICI)1098-108X(199907)

57. Westenhoefer J, von Falck B, Stellfeldt A, Fintelmann S. Behavioural correlates of successful weight reduction over $3 \mathrm{y}$. Results from the Lean Habits Study. Int J Obes Relat Metab Disord. 2004;28(2):334335. doi:10.1038/sj.ijo.0802530

58. Westenhoefe, J, Engel D, Holst C, Lorenz J, Peacock M, Stubbs J, et al. Cognitive and weight-related correlates of flexible and rigid restrained eating behaviour. Eating Behaviors. 2013;14(1):69-72. doi:10.1016/j.eatbeh.2012.10.015.

59. McGuire MT, Jeffery RW, French SA, Hannan PJ. The relationship between restraint and weight and weight-related behaviors among 
individuals in a community weight gain prevention trial. Internationa Journal of Obesity \& Related Metabolic Disorders. 2001;25(4):574580.

60. Tucker LA and L Bates. Restrained Eating and Risk of Gaining Weight and Body Fat in Middle-Aged Women: A 3-Year Prospective Study. American Journal of Health Promotion. 2009;23(3):187-194. doi:10.4278/ajhp.07061456.

61. Tylka TL and JA Wilcox. Are intuitive eating and eating disorder symptomatology opposite poles of the same construct? Journal of Counseling Psychology. 2006;53(4):474-485.

62. Tribole, E. and E. Resch, Intuitive eating. 3rd ed. New York: St Martin's Griffin. 2012;xxii:344

63. Van Dyke N, and EJ Drinkwater. Review Article Relationships between intuitive eating and health indicators: literature review. Public Health Nutr. 2014;17(8):1757-1766.doi:10.1017/S1368980013002139.

64. Augustus-Horvath CL and TL Tylka. The acceptance model of intuitive eating: A comparison of women in emerging adulthood, early adulthood, and middle adulthood. Journal of Counseling Psychology. 2011;58(1):110-125.doi:10.1037/a0022129.

65. Camilleri GM, Méjean C, Bellisle F, Andreeva VA, Sautron V, Hercberg $\mathrm{S}$ and et al. Cross-cultural validity of the Intuitive Eating Scale-2. Psychometric evaluation in a sample of the general French population. Appetite. 2015;84:34-42.doi:10.1016/j.appet.2014.09.009.

66. Denny KN, Loth K, Eisenberg ME, Neumark-Sztainer D. Intuitive eating in young adults. Who is doing it, and how is it related to disordered eating behaviors? Appetite. 2013;60(1):13-19.doi:10.1016/j. appet.2012.09.029.

67. Hawks S, Madanat H, Hawks J and Ashley Harris BS. The Relationship Between Intuitive Eating and Health Indicators Among College Women. American Journal of Health Education. 2005;36(6):331-336. DOI:10.1080/19325037.2005.10608206

68. Herbert BM, Blechert J, Hautzinger M, Matthias E, Herbert C Intuitive eating is associated with interoceptive sensitivity. Effects on body mass index. Appetite. 2013;70:22-30. doi:10.1016/j. appet.2013.06.082.

69. Madden CE, Leong SL, Gray A, Horwath CC. Eating in response to hunger and satiety signals is related to BMI in a nationwide sample of 1601 mid-age New Zealand women. Public Health Nutrition. 2012;15(12):2272-2279. doi:10.1017/S1368980012000882.

70. Shouse SH and J Nilsson. Self-silencing, emotional awareness, and eating behaviors in college women. Psychology of Women Quarterly. 2011;35(3):451-457. doi:10.1177/0361684310388785

71. Tylka, TL, RM Calogero and Daníelsdóttir S. Is intuitive eating the same as flexible dietary control? Their links to each other and well-being could provide an answer. Appetite. 2015;95:166-175. doi:10.1016/j.appet.2015.07.004

72. Keränen AM, Strengell K, Savolainen MJ and Laitinen JH. Effect of weight loss intervention on the association between eating behaviour measured by TFEQ-18 and dietary intake in adults. Appetite. 2011;56(1):156-162.doi:10.1016/j.appet.2010.10.004.

73. Lluch, A, NA King and JE Blundell. No energy compensation at the meal following exercise in dietary restrained and unrestrained women. Br J Nutr. 2000;84(2):219-225.

74. Keller $C$ and $M$ Siegrist. Successful and unsuccessful restrained eating. Does dispositional self-control matter? Appetite. 2014;74:101-106. doi:10.1016/j.appet.2013.11.019.

75. Teixeira PJ, Carraça EV, Marques MM, Rutter H, Oppert JM, De Bourdeaudhuij and et al. Successful behavior change in obesity interventions in adults: a systematic review-of self-regulation mediators. BMC Medicine. 2015;13(1):1-16.doi:10.1186/s12916015-0323-6.

76. Natalia S Lawrence, Frederick Verbruggen, Sinead Morrison, Rachel C Adams and Christopher D. Chambersb Stopping to food can reduce intake. Effects of stimulus-specificity and individual differences in dietary restraint. Appetite. 2015;85:91-103.doi:10.1016/j. appet.2014.11.006

77. Lowe MR. Dieting: proxy or cause of future weight gain? Obesity Reviews. 2015;16 suppl 2:19-24. doi: 10.1111/obr.12252.

78. Sacks FM, Bray GA, Carey VI, Smith SR, Ryan DH, Anton SD and et al. Comparison of Weight-Loss Diets with Different Compositions of Fat, Protein, and Carbohydrates. New England Journal of Medicine. 2009;360(9):859-873. doi:10.1056/NEJMoa0804748.

79. Anderson JW, Konz EC, Frederich RC, Wood CL. Long-term weightloss maintenance: a meta-analysis of US studies. Am J Clin Nutr. 2001;74(5):579-584.

80. Phelan S, Hill JO, Lang W, Dibello JR, Wing RR. Recovery from relapse among successful weight maintainers. Am J Clin Nutr. 2003;78(6):1079-1084.

81. Field AE, Austin SB, Taylor CB, Malspeis S, Rosner B, Rockett HR and Colditz GA. Relation Between Dieting and Weight Change Among Preadolescents and Adolescents. Pediatrics. 2003;112(4):900-906.

82. Siahpush M, Tibbits M, Shaikh RA, Singh GK, Sikora Kessler A, Huang TT. Dieting Increases the Likelihood of Subsequent Obesity and BMI Gain: Results from a Prospective Study of an Australian National Sample. International Journal of Behavioral Medicine. 2015;22(5):662-671.doi:10.1007/s12529-015-9463-5.

83. Carper JL, JO Fisher, and LL Birch. Young girls' emerging dietary restraint and disinhibition are related to parental control in child feeding. Appetite. 2000;35(2):121-129. 